\title{
Geotechnical Characteristics of Bentonite/Sandy Silt Mixes for Use in Waste Disposal Sites
}

\author{
W. V. Abeele
}

\section{DISCLAIMEP}

This report was prepared as an account of work sponsored by an agency of the United States Government. Neither the United States Government nor any agency thereof, nor any of their employees, makes any warranty, express or implied, or assumes any legal liability or responsibility for the accuracy, completeness, or usefulness of any information, apparatus, product, or process disclosed, or represents that its use would not infringe privately owned rights. Reference herein to any specific commercial product, process, or service by trade name, trademark, manufacturer, or otherwise does not necessarily constitute or imply its endorsement, recommendation, or favoring by the United States Government or any agency thereof. The views and opinions of authors expressed herein do not necessarily state or seflect those of the United States Government or any agency thereof. 


\title{
GEOTECHNICAL CHARACTERISTICS OF BENTONITE/SANDY SILT MIXES FOR USE IN WASTE DISPOSAL SITES
}

\author{
by
}

\author{
W. V. Abeele
}

\begin{abstract}
The coefficient of consolidation for bentonite/sandy silt ratios of 0.04 to 0.14 decreases inversely proportional with the square of that ratio, whereas the compression index, the swelling index, and the permeability change index increase with increasing bentonite ratio. A strong relationship also exists between the void ratio and the logarithm of the applied stress for any given bentonite ratio. The empirical linear relationship between the void ratio and the logarithm of the applied stress, developed by Taylor, is excellent and enables us to limit the evaluation of conductivity at any void ratio to the measurement of the initial and the desired void ratio, the initial conductivity, and the permeability change index. This allows us to read directly, for a given bentonite ratio, the void ratio (or compaction) needed so that a required hydraulic conductivity will prevail. This is crucial in the choice of materials or mixes to be used in a wick system where an established differentiation in hydraulic conductivity is desirable.
\end{abstract}

\section{INTRODUCTION}

The permeability of waste disposal facility liners and caps, i.e., moisture barriers, is important in geotechnical engineering. Permeability is the dominant parameter in the design and implementation of waste disposal facilities. Clay is prominent among the materials usually considered to line or cap disposal pits. Foremost among the problems connected with the use of clays is cracking during periods of desiccation, although both the Environmental Protection Agency (EPA) and the Nuclear Regulatory Commission (NRC) seem to feel that clays, as barriers to water leachate migration and inflow of water, are the principal materials to be considered as liners and caps in waste disposal facilities. Clays and soils, in general, also offer by far the longest service life of any liner material.

Use of clay mixes instead of pure clays may be warranted-not solely on the basis of economics; mechanical benefits may even become overriding in mandating the use of mixes. In Los Alamos, New Mexico, the use of local tuff (texture of sandy silt,* Abrahams 1963) with low amounts of bentonite appeared to be very promising in greatly decreasing hydraulic conductivity without showing any of the mechanical impairments of clays. Saturated Na-bentonite absorbs water up to 5 times its own mass to form a gel up to 15 times its own dry volume. Besides being less expensive, a liner or cap, consisting of a mix of the local medium and bentonite clay, probably would not crack when desiccated. Cracking from desiccation can be further minimized by proper compaction. A low hydraulic conductivity, combined with acceptable mechanical characteristics, should be obtainable at some ideal mix of two materials, each possessing one or the other property'. The objective of this research is to obtain the necessary data to assure that the use of such a mixture (e.g., sandy

*Sandy silt: an unconsolidated sediment containing $10-50 \%$ sand and having a ratio of silt to clay greater than 2:1 (Folk 1954). 
silt/bentonite) is effective in isolating waste from the environment. This research will also tell us the respective ratios at which ideal hydraulic and mechanical characteristics may be expected. Laboratory tests were performed at $22^{\circ} \mathrm{C} \pm 2{ }^{\circ} \mathrm{C}$. The bentonite used in our experiments was 13-T and was obtained from the International Minerals \& Chemical Corporation, Des Plaines. Illinois.

\section{EVALUATION OF PERMEABILITY FROM CONSOLIDATED TESTS}

It has been ascertained that the coefficient of consolidation of a soil sample under stress is related to its permeability. Consolidation rates have, therefore, been considered as a means of indirect evaluation of soil permeability (Olson and Daniel 1981). Consolidation tests can be routinely performed in geotechnical evaluations of construction sites. and permeabilities at initial void ratio, $e_{o}$, or any void ratio corresponding to a known applied stress, $\sigma$, can readily be derived.

In our case, the permeability, $\mathrm{k}$, was derived from the coefficient of consolidation, $C_{v}$, which was measured in step-loaded oedometer tests. Terzaghi's theory, used in the interpretation of consolidation rates in terms of permeability, is based on assumptions that do not necessarily fit actual soil behavior properly. Terzaghi's theory is based, according to Head (1982), on the following assumptions:

"I. The layer of soil being consolidated is horizontal, homogeneous, of uniform thickness, and is laterally confined.

2. The soil is fully saturated.

3. Soil particles and water are incompressible.

4. Darcy's law for the flow of water through soil is valid.

5. The coefficient of permeability and other soil properties remain constant during any one increment of applied stress.

6. The applied pressure is uniform along a horizontal plane.

7. Flow of water takes place only in a vertical direction, i.e., drainage and compression are onedimensional.

8. A change in effective stress in the soil causes a corresponding change in voids ratio and their relationship is linear during any one stress increment.
9. The initial excess pore pressure due to the application of load is uniform throughout the depth of the clay layer.

10. The extended duration of the consolidation period is due entirely to the low permeability of the soil.

11. One or both of the strata adjacent to the clay layer are perfectly free-draining in comparison with the clay.

12. The weight of the soil itself may be neglected."

The fifth of the above assumptions cannot be validated for sandy silt/bentonite mixes. Assumption (3) is partly unfulfilled because soil particles can be compressed. (This is generally thought to be of little consequence.) Assuming these requirements are fulfilled, the permeability may be derived from the one-dimensional consolidation equation so that

$$
C_{v}=\frac{k}{m_{v} \gamma_{w}}
$$

and

$k=C_{v} m_{v} \gamma_{w}$

with $\mathbf{m}_{\mathbf{v}}=$ coefficient of volume compressibility and $\gamma_{w}=$ unit weight of water. If the soil is not saturated, rapid "consolidation" will be observed, except "consolidation" is really compression of gas bubbles. Consequently, excessive values of $C_{v}$ and $k$ are measured if the soil is not saturated.

One of the liabilities one faces when using Terzaghi's step-loaded method lies in the assumption that $\mathrm{k}, \mathrm{C}_{\mathrm{v}}$, and $\mathrm{m}_{\mathrm{v}}$ remain constant during that particular consolidation load step (Tavenas et al. 1979). Both $C_{v}$ and $m_{v}$ show a tendency to decrease with increasing stress (Abeele 1984) and there is no reason to doubt that the behavior would be different as the void ratio is reduced during any particular consolidation step. Tavenas et al. (1983, Part I) show that the coefficient of consolidation may decrease by more than a factor of 4 during a particular clay consolidation load step. The variability of the coefficient of consolidation with changing stress is not as drastic when the clay content in the soil decreases. No trend in the $C_{\mathrm{u}}$ values was detected for any of the lower bentonite/crushed tuff ratios considered in this study. Therefore, the coefficients of consolidation computed for each stress were averaged and used as the mean coefficient of consolidation at a particular 
mixing ratio. Table I shows decreasing $C_{v}$ values with increasing bentonite/tuff ratios, $R$, whereas the $m_{v}$ values are more susceptible to changing stresses. The relationship between $C_{v}$ and $R$ can be written as

$C_{v}=0.06 R^{-2}$ with $r^{2}=0.99$

To ensure that $C_{v}$ is more or less constant uuring any load increment, the applied stress increase is never more than double the previous applied stress. Table II indicates the relationship, based on Eq. (1), of the computed values of $k$ to $R$ for a particular stress. The computed hydraulic conductivity is expressed in $10^{-10} \mathrm{~ms}^{-1}$.
In view of the liabilities we encountered when deriving hydraulic conductivities by application of the consolidation method and considering the difficulties in determining the coefficient of consolidation at lower bentonite contents, direct measurement of conductivity was also jerformed using the constant head method. At low bentonite ratios, the consolidation rate is too fast to be measured with any degree of accuracy.

During consolidation of pure crushed tuff (sandy silt), the void ratio-log time curves were concave upward from the start, indicating extremely fast consolidation and subsequent low degree of accuracy. The coefficient of consolidation averaged $8.7 \cdot 10^{4}$ $\mathrm{m}^{2} \mathrm{~s}^{-1}$ for repetitive stresses of $50,100,200,400$, and

TABLE I

\section{$m_{v}$ AND AVERAGE $C_{v}$ VALUES FOR VARYING MIXING RATIOS AND STRESSES}

\begin{tabular}{|c|c|c|c|c|}
\hline \multirow[b]{2}{*}{$\mathbf{R}$} & \multirow[b]{2}{*}{$\sigma(\mathbf{k P a})$} & \multicolumn{2}{|c|}{$C_{v}\left(10^{-8} \mathrm{~ms}^{-1}\right)$} & \multirow[b]{2}{*}{$\mathrm{m}_{\mathrm{r}}\left(10^{-6} \mathrm{~Pa}^{-1}\right)$} \\
\hline & & $\overline{\mathbf{x}}$ & $\mathbf{s}$ & \\
\hline \multirow[t]{4}{*}{0.04} & 100 & & & 34.5 \\
\hline & 200 & 41.6 & 6.18 & 20.3 \\
\hline & 400 & & & 12.2 \\
\hline & 800 & & & 7.1 \\
\hline \multirow[t]{4}{*}{0.06} & 100 & & & 39.1 \\
\hline & 200 & 18.2 & 5.90 & 30.2 \\
\hline & 400 & & & 18.1 \\
\hline & $\therefore 800$ & & & 10.0 \\
\hline \multirow[t]{4}{*}{0.075} & 100 & & & 66.3 \\
\hline & 200 & 11.6 & 4.84 & 39.7 \\
\hline & 400 & & & 22.7 \\
\hline & 800 & & & 11.5 \\
\hline \multirow[t]{4}{*}{0.09} & 100 & & & 43.5 \\
\hline & 200 & 8.0 & 6.20 & 37.2 \\
\hline & 400 & & & 22.5 \\
\hline & 800 & & & 14.6 \\
\hline \multirow[t]{4}{*}{0.11} & 100 & & & 40.3 \\
\hline & 200 & 5.3 & 3.29 & 43.0 \\
\hline & 400 & & & 23.4 \\
\hline & 800 & & & 13.6 \\
\hline \multirow[t]{4}{*}{0.14} & 100 & & & 40.0 \\
\hline & 200 & 3.2 & 0.72 & 43.0 \\
\hline & 400 & & & 25.9 \\
\hline & 800 & & & 13.4 \\
\hline
\end{tabular}


TABLE II

\section{SATURATED HYDRAULIC CONDUCTIVITY $\left(10^{-10} \mathrm{~m}^{-1}\right)$ EXPRESSED AS A FUNCTION OF MIXING RATIOS FOR DIFFERENT CONSOLIDATION PRESSURES}

\begin{tabular}{|c|c|c|}
\hline $\begin{array}{l}\text { Stress } \\
\text { (kPa) }\end{array}$ & $\hat{\mathbf{k}}$ & $r^{2}$ \\
\hline 100 & $0.021 R^{-2.098}$ & 0.996 \\
\hline 200 & $0.024 \mathrm{R}^{-1.968}$ & 0.995 \\
\hline 400 & $0.015 R^{-1.934}$ & 0.996 \\
\hline 800 & $0.009 R^{-1.910}$ & 0.996 \\
\hline
\end{tabular}

$800 \mathrm{kPa}$. An analysis of variance detected no trend in $C_{v}$ with increasing stress because of the high values of the standard deviations for $\mathrm{C}_{\mathrm{v}}$ at $0 \%$ bentonite. The conductivities obtained using the constant head method on uncompacted tuff $(0 \mathrm{kPa})$ with low bentonite ratios (0-0.04) are in general agreement with the results obtained using the consolidation method for higher bentonite ratios (0.4-0.14). This is demonstrated in Fig. 1.

Table II shows, for varying consolidation pressures, the close exponential relationship existing between $\mathrm{R}$ as independent variable and $\mathrm{k}$ as dependent variable (all $r^{2}$ are better than 0.99 !). That trend is displayed linearly on a log-log plot in Fig. 2, with k decreasing with increasing clay fraction. Figure 2 contains only the results obtained using the consolidation method and $R$ values varying from 0.04 to 0.14 . The results obtained using the constant head method $(0 \mathrm{kPa})$ are not shown in Fig. 2 because the regression equation showing the best fit is not an exponential one. The best fit for uncompacted mixes ( $R=0$ to 0.04$)$ is $\log k=5.065-94.298 R$, with $r^{2}=$ 0.982 and $\mathrm{k}$ in $10^{-10} \mathrm{~m} \mathrm{~s}^{-1}$. Figures 1 and 2 further demonstrate that hydraulic conductivity is not only a function of particle size distribution or varying bentonite ratio, but also of void ratio (or applied stress). The conductivity of a porous material obviously decreases with void ratio. c, and e. in turn, decreases with increasing compaction pressure or stress, $\sigma$. The former is clearly shown in Table III and Fig. 3. Direct measurement of hydraulic conductivity using either the constant head method or the consolidation method produces a linear e vs $\log k$ relationship. A predictive empirical linear relationship between log $\mathrm{k}$ and $\mathrm{e}$ was first proposed by Taylor (1948)

$\log k=\log k_{o}-\frac{e_{0}-e}{C_{k}}$ where $\mathrm{k}_{\mathrm{o}}$ and $\mathrm{e}_{\mathrm{o}}$ may be in situ, remolded, or known preconsolidated values and $C_{k}$ is a permeability change index. This type of relationship has become regarded as the most accurate way of expressing the variation of permeability with void ratio (Tavenas et al. 1983, Part II). The linear relationship between log $k$ and extends beyond strains of $20 \%$ for sandy silt/bentonite mixes, whereas Tavenas et al. (1983, Part II) limit the validity of this relationship to strains of less than $20 \%$ for most natural soft clays.

The interrelationship between $\log \mathrm{k}$ and $\mathrm{e}$ is very important in the study of materials in caps or liners that can in any way influence the migration of pollutants from waste disposal pits. Indeed, in a homogenized material with uniform grain size distribution (as the one likely to be used to line or cap a waste disposal pit), the porosity would be the only variable to influence the conductivity. The slope of the void ratio vs $\log \mathrm{k}$ is defined as the permeability change index. $C_{k}$ (Tavenas et al. 1983. Part II). Table IV scems to indicate that the permeability change index, $C_{k}$, and the compression index, $C_{c}$, are both increasing with increasing bentonite ratio. (The compression index, $C_{c}$, is the slope of the straight line, where $\left.e=-C_{c} \log \sigma / \sigma_{o}\right)$. The values for the $C_{c} / C_{k}$ ratio average 0.677 , with $\mathrm{s}=0.035$ or a $\mathrm{CV}$ (coefficient of variation) of $5.1 \%$.

A linear relationship can be established between $C_{k}$ and $C_{c}$ with

$C_{k}=-0.053+1.706 C_{c}$

with $r^{2}=0.983$.

For sandy silt/bentonite mixes. $C_{k}$ relates to $e_{o}$ as

$C_{k}=-0.835+1.585 e_{o}$. 


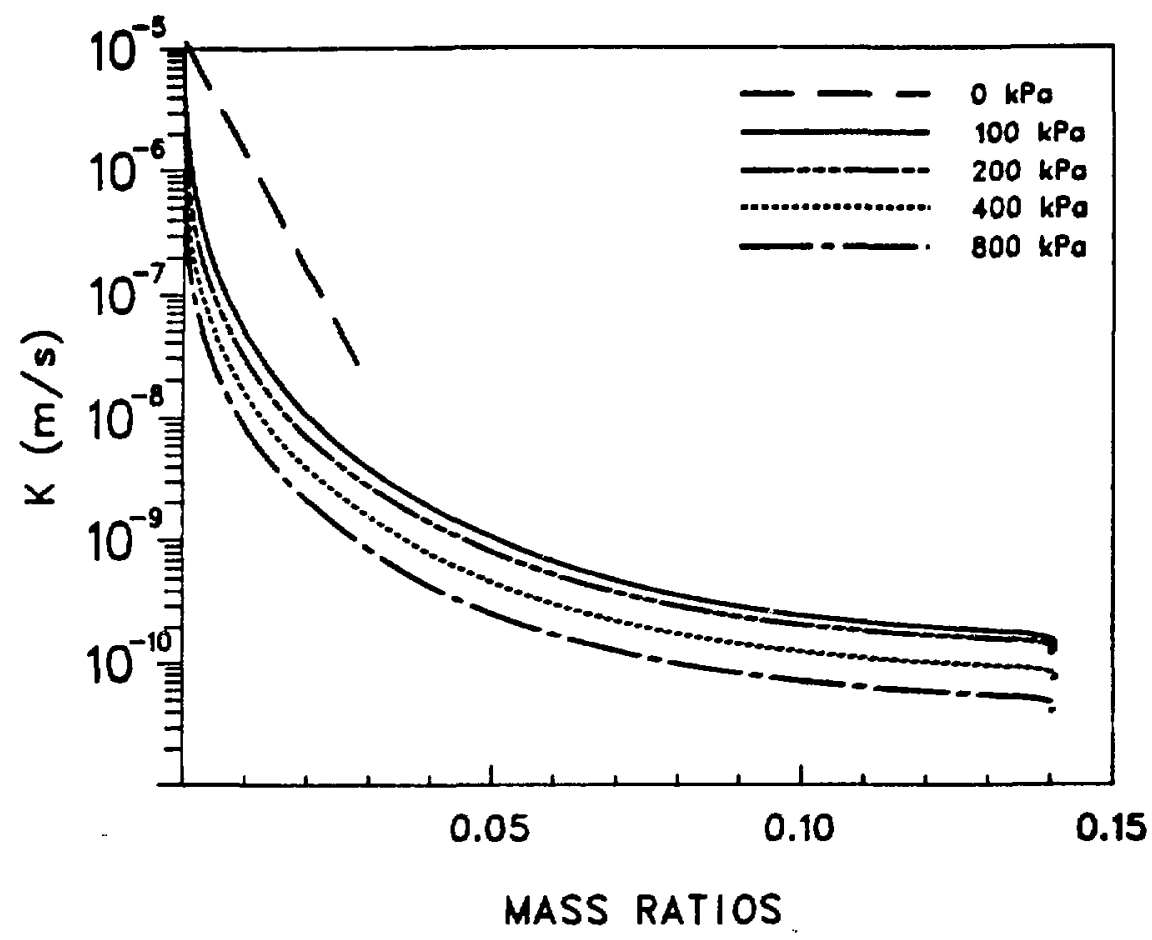

Fig. 1. Hydraulic conductivity as a function of bentonite/sandy silt ratios.

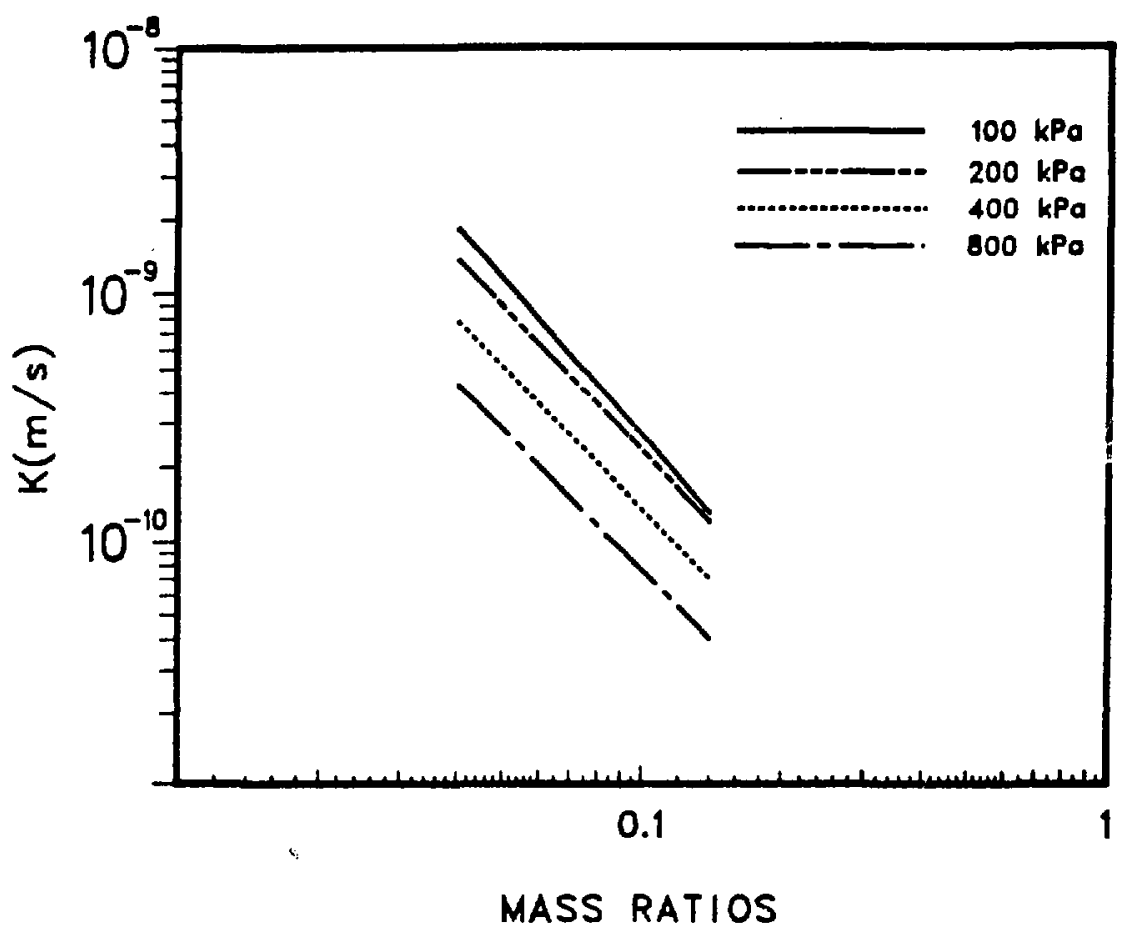

i. 2. Hydraulic conductivity as a function of bentonite/sandy silt ratios. 
TABLE III

\section{HYDRAULIC CONDUCTIVITY (in $10^{-12} \mathrm{~ms}^{-1}$ ) \\ AS A FUNCTION OF VOID RATIOS \\ FOR VARYING CLAY CONTENTS}

\begin{tabular}{|c|c|c|}
\hline $\mathbf{R}$ & $\log k$ & $r^{2}$ \\
\hline 0.00 & $2.722 \mathrm{e}+4.499$ & 0.846 \\
\hline 0.04 & $4.893 e+0.406$ & 0.980 \\
\hline 0.06 & $3.871 e+0.132$ & 1.000 \\
\hline 0.075 & $2.519 e+0.918$ & 0.965 \\
\hline 0.09 & $2.274 e+0.814$ & 0.960 \\
\hline 0.11 & $2.107 c+0.713$ & 0.954 \\
\hline 0.14 & $1.916 e+0.559$ & 0.946 \\
\hline
\end{tabular}

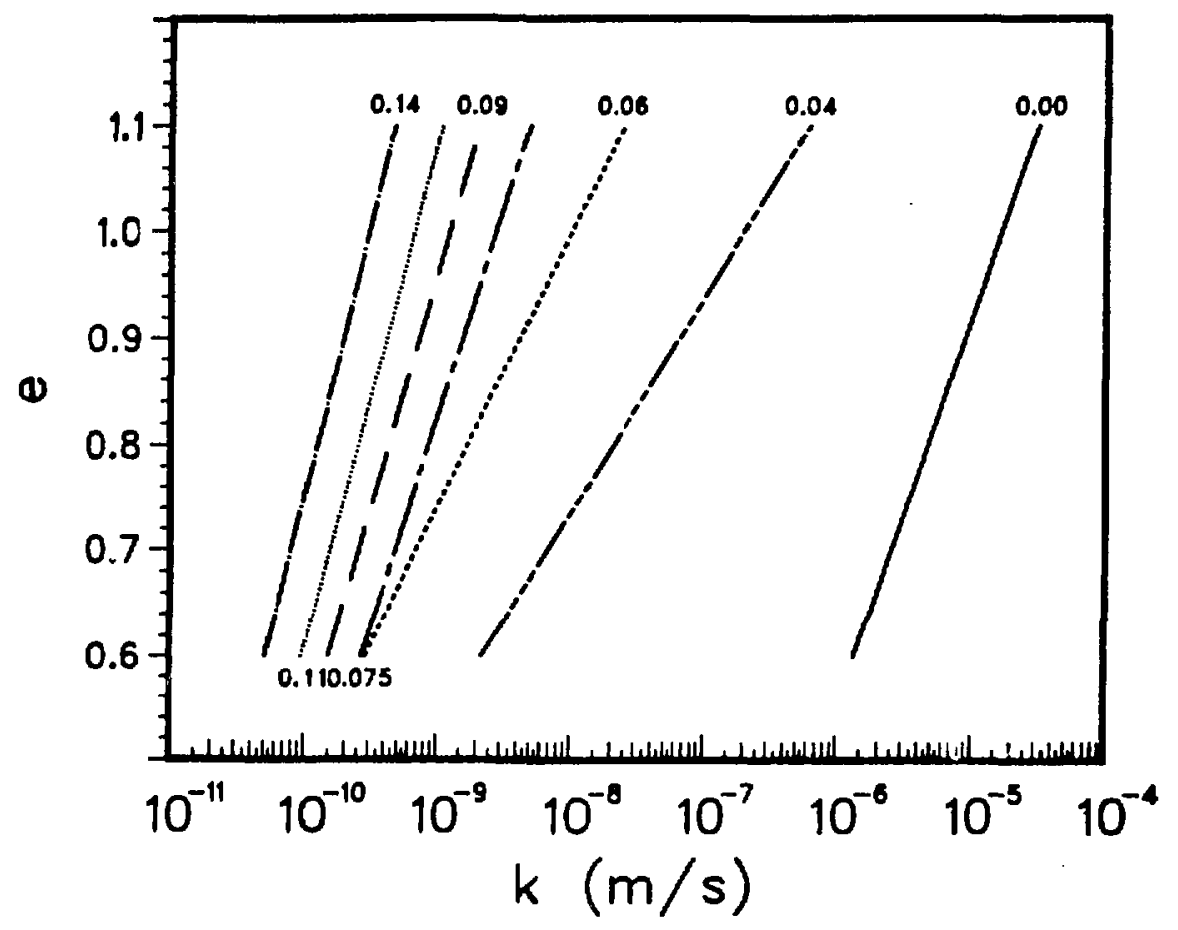

Fig. 3. Hydraulic conductivity as a function of void ratios for varying clay contents. 


\section{TABLE IV}

\section{COMPRESSION INDEX, PERMEABILITY CHANGE INDEX, AND DERIVED RELATIONSHIPS AS A FUNCTION OF CLAY RATIOS}

\begin{tabular}{|c|c|c|c|c|c|}
\hline $\mathbf{R}$ & $\mathrm{C}_{\mathrm{c}}$ & $C_{k}$ & $C_{c} / C_{k}$ & $1 / C_{c}-1 / C_{k}$ & $1 /\left(1 /+e_{0}\right)$ \\
\hline 0.04 & 0.145 & 0.200 & 0.722 & 1.926 & 0.569 \\
\hline 0.06 & 0.210 & 0.304 & 0.692 & 1.463 & 0.571 \\
\hline 0.075 & 0.259 & 0.383 & 0.676 & 1.251 & 0.581 \\
\hline 0.09 & 0.280 & 0.401 & 0.697 & 1.084 & 0.564 \\
\hline 0.11 & 0.292 & 0.453 & 0.646 & 1.213 & 0.557 \\
\hline 0.14 & 0.311 & 0.494 & 0.629 & 1.196 & 0.542 \\
\hline
\end{tabular}

No apparent relationship seems to link the $C_{c} / C_{k}$ ratio with the void ratio, e.

According to Tavenas et al. (1983, Part II), the condition for a constant $\mathrm{C}_{v}$ during consolidation may be written

$$
\frac{1}{C_{c}}-\frac{1}{C_{k}}=\frac{1}{1+e_{o}}
$$

As can be seen from Table IV, the left side of the equation exceeds the right side by a factor of 2 or 3 , thus failing once more to invalidate Terzaghi's assumption of the constancy of $\mathrm{C}_{\mathrm{v}}$ during any particular loading step. This requirement had to be fulfilled for the consolidation method to be valid for the computation of $k$. However, our practical results using the consolidation method show a good compatibility with the results obtained using the constant head method or with the ones obtained by Daniel and Olson (1980) when using the same materials (tuff + bentonite). In fact, the results obtained by Daniel and Olson at $0 \mathrm{kPa}$ are identical to our results at $400 \mathrm{kPa}$.

The predictive empirical linear relationship between log $k$ and e first proposed by Taylor (1948) [Eq. (3)] allows us to compare the predicted (Taylor) vs measured hydraulic conductivities (in $10^{-12} \mathrm{~ms}^{-1}$ ) using the consolidation method. In no case did the discrepancy between the two methods amount to $3.5 \%$ (see Table V).

\section{CONSOLIDATION AND SWELLING}

The consolidation data were readily available because the computation of the hydraulic conductivity, in accordance with Terzaghi's theory, required measurement of the consolidation. Table VI shows how the void ratio, e, varies as a function of stress, $\sigma$ (or pressure), for different bentonite ratios, $R$. The goodness of fit of the data to the equation is expressed by the coefficient of determination $r_{e}^{2}(\log \sigma)$.

$\mathrm{C}_{c}$ and $\mathrm{S}_{c}$ are the consolidation and swelling indices obtained for different bentonite ratios. Figure 4 shows how both increase with increasing bentonite ratios. The $S_{c} / C_{c}$ ratio averages 0.117 , with a standard deviation of 0.018 or a coefficient of variation close to $16 \%$. A linear relationship established between $S_{c}$ and $C_{c}$ yields $S_{c}=-0.005+0.140 C_{c}$ and $r^{2}=0.823$.

\section{EVALUATION OF CHEMICAL INTERAC- TIONS}

Direct measurement of conductivity using the constant head method enabled us to evaluate eventual chemical interactions between influent and the bentonite/crushed tuff mix. In the case of pure crushed tuff ( $C E C=0.3 \mathrm{meq} / 100 \mathrm{~g}$ ), the effluent indicates that tuff contains a high concentration of water soluble sodium relative to concentrations of water soluble calcium and magnesium. Concentrations of $\mathrm{Na}, \mathrm{Ca}$, and $\mathrm{Mg}$ in influent and effluent were measured using inductively coupled plasma spectrometry and flame atomic absorption.

On leaching the initially $\mathrm{Na}$-saturated bentonite mixes with tap water ( $50 \mathrm{ppm} \mathrm{Ca}, 5 \mathrm{ppm} \mathrm{Mg}$, and 16 ppm $\mathrm{Na}$ ), exchange sites eventually became saturated with $\mathrm{Ca}$. Data for $1 \%$ bentonite indicate that the originally higher effluent $\mathrm{Na}$-concentration is equal to influent $\mathrm{Na}$-concentration after approximately 20 pore volumes, suggesting a probable Ca-saturation. However, it should be noted that $\mathrm{Ca}$ is still less concentrated in the effluent than in the influent, which could indicate that concentration is controlled by precipitation. Sodium, because of its large hydration radius, is the primary cause of the sealing powers of bentonite. 
TABLE V

PREDICTED (TAYLOR) AND MEASURED HYDRAULIC CONDUCTIVITIES (in $10^{-12} \mathrm{~ms}^{-1}$ ) AS A FUNCTION OF VOID RATIO FOR VARYING CLAY RATIOS

\begin{tabular}{|c|c|c|c|}
\hline $\mathbf{R}$ & $\begin{array}{c}\mathbf{k} \\
\text { Predicted }\end{array}$ & $\begin{array}{c}\mathbf{k} \\
\text { Measured }\end{array}$ & $\frac{\mathbf{K}_{\mathbf{m}}-\mathbf{K}_{\mathbf{z}}}{\mathbf{k}_{\mathbf{m}}}$ \\
\hline 004 & 2.613 & 2.636 & 0.009 \\
\hline & & & 0.013 \\
\hline 0.075 & 2. & 2.1 & 0.016 \\
\hline 0.09 & & & 0.035 \\
\hline 0.1 & 1.7 & 1.7 & 0.022 \\
\hline 0.14 & 1.626 & 1.602 & -0.015 \\
\hline
\end{tabular}

\section{TABLE VI}

CONSOLIDATION AND SWELLING OF BENTONITE/SANDY SILT MIXES

\begin{tabular}{|c|c|c|c|c|c|}
\hline $\mathbf{R}$ & $\mathbf{e}$ & $r^{2} e(\log \sigma)$ & $\mathbf{C}_{\mathrm{c}}$ & $\mathbf{S}_{\mathbf{c}}$ & $\mathbf{S}_{\mathrm{c}} / \mathrm{C}_{\mathrm{c}}$ \\
\hline 0.00 & $0.915-0.129 \log \sigma$ & 0.993 & 0.129 & $0.0 ! 6$ & 0.108 \\
\hline 0.04 & $1.047-0.145 \log \sigma$ & 0.994 & 0.145 & 0.013 & 0.121 \\
\hline 0.06 & $1.171-0.210 \log \sigma$ & 0.996 & 0.210 & 0.021 & 0.101 \\
\hline 0.075 & $1.240-0.259 \log \sigma$ & 0.999 & 0.259 & 0.025 & 0.096 \\
\hline 0.09 & $1.333-0.280 \log \sigma$ & 0.990 & 0.280 & 0.033 & 0.119 \\
\hline 0.11 & $1.381-0.292 \log \sigma$ & 0.997 & 0.292 & 0.035 & 0.121 \\
\hline 0.14 & $1.465-0.311 \log \sigma$ & 0.998 & 0.311 & 0.047 & 0.151 \\
\hline
\end{tabular}

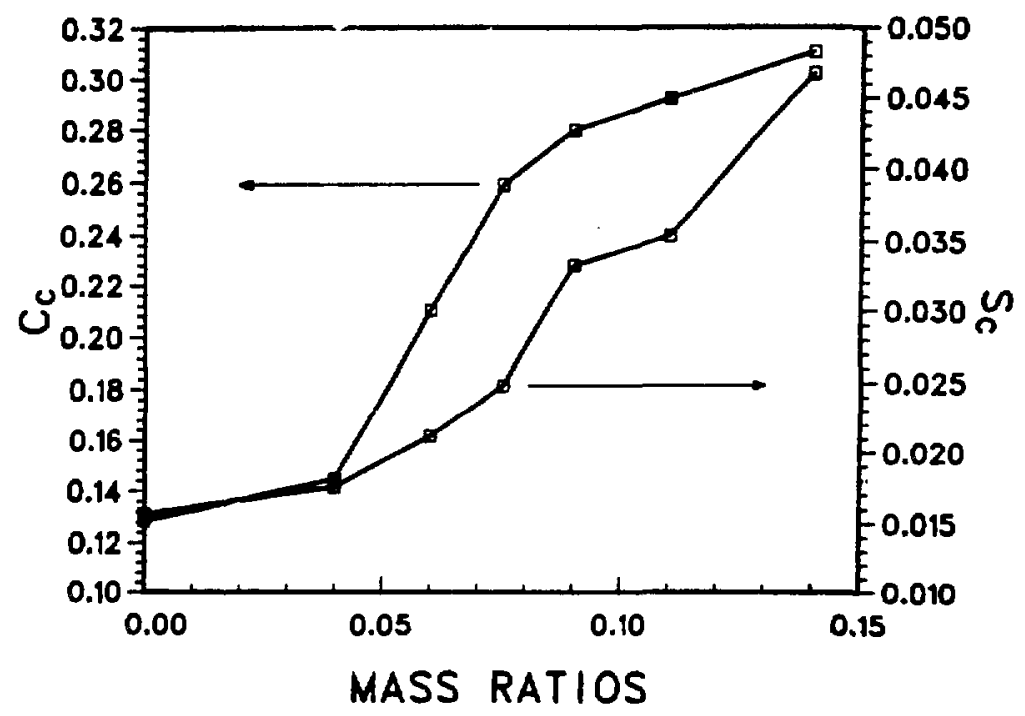

Fig. 4. Consolidation and swelling indices as a function of bentonite/sandy silt ratios. 
Increases in permeability with leaching time were observed with 1 and $2 \%$ bentonite. Equilibrium was reached after 3 pore volumes. No changes in permeability occurred in the 3 and $4 \%$ bentonite mixes. To evaluate the effect of sodium on permeability, $1 \mathrm{M} \mathrm{NaCl}$ was added to the 1 and $2 \%$ mixes after constant hydraulic concluctivities were observed. Sodium equilibrium (effluent concentration $=$ influent concentration) was reached within 3 pore volumes, indicating the bentonite/sandy silt mix was Na-saturated. No further changes in hydraulic conductivity took place in the mix containing $1 \%$ bentonite. Paradoxically, addition of $1 \mathrm{M}$ $\mathrm{NaCl}$ increased the hydraulic conductivity of the $2 \%$ bentonite mix. Redispersion, caused by $\mathrm{Na}$ saturation, led us to expect a decreased permeability. Increased permeability may be caused through overcrowding by the sodium ions.

In the case of the 3 and $4 \%$ bentonite mixes, there was a very steady decrease of a relatively high $\mathrm{Na}$-concentration in the effluent. The decrease in $\mathrm{Na}$ concentration averaged a factor of 8 per pore volume. Such a change in Na-concentration suggests a significant change in $\mathrm{Na}$ adsorbed to exchange sites without any significant effect on permeability.

\section{CONCLUSIONS}

- The coefficient of consolidation decreases inversely proportional with the square of the bentonite/tuff ratio. This relationship has been validated for bentonite/tuff ratios in the 0.04 to 0.14 range. The coefficient of volume compressibility is more susceptible to changing stresses and is inversely related to it.

- The hydraulic conductivity. when expressed as a function of mixing ratios, shows a steeper decrease at lower consolidation pressures. This is indicated in Fig. 2 but is not consequential enough to be clearly visible. Table II shows a trend that is clear (exponent varying from -2.10 to -1.91 ) but not strong enough to enable us to draw any conclusions.

- The compression index, $C_{\mathrm{c}}$; the swelling index, $\mathrm{S}_{\mathrm{r}}$ : and the permeability change index, $C_{k}$, increase with increasing bentonite ratio. Although a reasonably accurate prediction of $S_{c}$ can be made based on known values of $C_{c}\left(S_{c}=0.14 C_{c}\right)$, regression analyșis shows that a much better relationship exists between $C_{k}$ and $C_{c}$. The permeability change index can be predicted to be close to -0.05 $+1.71 \mathrm{C}_{c}$.

- A strong relationship exists between the void ratio and $\log \sigma$ (stress) for each bentonite ratio.

- Several indicators lead us to believe in the eventual inadequacy of Terzaghi's method for the computation of conductivity $\left[\right.$ e.g., $1 / C_{c}-1 / C_{k} \neq 1 /\left(1+e_{o}\right)$, the variability of $C_{v}$ and $m_{v} \ldots$. .

Howcver, results obtained using the constant head method or obtained by Daniels and Olson (1980) confirm the validity of the consolidation method.

- The predictive empirical linear relationship between $\log \mathrm{k}$ and $\mathrm{e}$, where

$$
\log k=\log k_{o}-\frac{e_{o}-e}{C_{k}}
$$

is excellent and enables us to limit the evaluation of conductivity at any void ratio to the measurement of the initial and the desired void ratio, the initial conductivity, and the permeability change index.

- The data shown in Fig. 3 enable us to read directly, for a given bentonite ratio, the void ratio (or compaction) necessary to obtain a required hydraulic conductivity. This is crucial in our choice of materials or mixes to be used in a wick system where an established differentiation in hydraulic conductivity is desirable.

- The hydraulic conductivity of a mix of $10 \%$ bentonite or more is nearly equal to that of pure bentonite. Conductivities in the $10^{-10} \mathrm{~ms}^{-1}$ are common for bentonites. The strong impact of small amounts of Na-bentonite is probably because bentonite solids may form a gel or paste that fills most of the voids of the aggregati

\section{ACKNOWLEDGMENTS}

Thanks are due to $W$. J. Herrera for equipment set up, to E. J. Cokal and R. D. Walker for the chemical analysis, W. L. Polzer for interpretation of the chemical interactions, and G. J. Langhorst for computer plotting. 


\section{REFERENCES}

Abeele, W. V., "Geotechnical Aspects of Hackroy Sandy Loam and Crushed Tuff," Los Alamos National Laboratory report LA-9916-MS (1984).

Abrahams, J. H., Jr., "Physical Properties of and Movement of Water in the Bandelier Tuff, Los Alamos and Santa Fe Counties, N.M.," US Department of the Interior Geological Survey, Albuquerque, New Mexico (January 1963).

Daniel. D. E., and R. E. Olson, "Geotechnical Aspects in Design of Disposal Sites for Low-Level Radioactive Wastes," Texas Section Meeting, American Society of Civil Engineers, San Antonio, Texas (April 24, 1980).

Folk, Robert L., "The Distinction Between Grain Size and Mineral Composition in Sedimentary-Rock Nomenclature," Journal of Geology 62, 344-359 (1954).

Head, K. H., Manual of Soil Laboratory Testing, Vol. 2 (Haisted Press Book, John Wiley \& Sons, Inc., New York 1981).
Olson, R. E., and D. E. Daniel, "Measurement of the Hydraulic Conductivity of Fine Grained Soils," ASTM special technical publication 746 (1981), pp. 18-64.

Tavenas, F., M. Brucy, J. P. Magnan, P. LaRochelle, and M. Roy, "Analyse critique de la théorie de consolidation unidimensionnelle de Terzaghi," Revue Francaise de Géotechnique, No. 7, pp. 29-43 (1979).

Tavenas, F., P. Leblond, P. Jean, and S. Leroueil, "The Permeability of Natural Soft Clays. Part I: Methods of Laboratory Measurement," Canadian Geotechnical Journal 20(4), 629-644 (1983).

Tavenas, F., P. Jean, P. Leblond, and S. Leroueil, "The Permeability of Natural Soft Clays. Part II: Permeability Characteristics," Canadian Geotechnical Journal 20(4), 645-660 (1983).

Taylor, D. W., Fundamentals of Soil Mechanics (John Wiley \& Sons, Inc., New York, 1948). 